\title{
Analysis and risk assessment of the supply of copper ore in the belt conveyor system in an underground mine
}

\author{
Anna BURDUK ${ }^{1}$, Dorota WIECEK ${ }^{2}$, Ivan ZAJAČKO ${ }^{3}$, Leszek JURDZIAK ${ }^{1}$ \\ and Ryszard BEA $\dot{Z} E J^{1}$
}

Authors' affiliations and addresses:

${ }^{1}$ Wrocław University of Science and Technology, ul. Wybrzeże Wyspiańskiego 27, 50-370

Wrocław, Poland

e-mail: anna.burduk@pwr.edu.pl

e-mail: leszek.jurdziak@pwr.edu.pl

e-mail: ryszard.blazej@pwr.edu.pl

${ }^{2}$ University of Bielsko-Biala, ul. Willowa 2, 43 309 Bielsko-Biała, Poland

e-mail: dwiecek@ath.bielsko.pl

${ }^{3}$ University of Žilina, Univerzitná 1, 01026

Žilina, Slovak Republic

e-mail: ivan.zajacko@fstroj.uniza.sk

*Correspondence:

Anna Burduk, Wrocław University of Science and Technology, ul. Wybrzeże Wyspiańskiego

27, 50-370 Wrocław, Poland

tel.:+48 713203710

e-mail:anna.burduk@pwr.edu.pl

How to cite this article:

Burduk, A., Więcek, D., Zajačko, I., Jurdziak, L. and Błażej, R. (2020). Analysis and risk assessment of the supply of copper ore in the belt conveyor system in an underground mine. Acta Montanistica Slovaca, Volume 25 (2), 236-249

DOI:

https://doi.org/10.46544/AMS.v25i2.10

\begin{abstract}
Risk management, through the systematic implementation of policies related to analysis, assessment, and action leading to a reduction in the amount of risk-related losses, is increasingly used in manufacturing companies. We are looking for opportunities in order to improve efficiency and an opportunity of gaining a competitive advantage in reducing the risk level of having a negative impact on the economic results of enterprises. The article presents the concept of reliable analysis and risk assessment for the horizontal transport system of copper ore. The risk has been defined as the probability of not achieving the objective set for the transport system, i.e., not delivering the planned amount of copper ore in a given time to the mining shaft. Unplanned downtime and belt conveyor failures have been assumed as risk factors. The proposed method consists of three stages. The FMEA (Failure Mode and Effects Analysis) method was used in the first stage, which allowed for the designation of structural elements of the belt conveyor, which are most often damaged. The FMEA method uses operational data collected over a period of three years as well as the expert knowledge of maintenance staff. In the second stage, the transport system was divided into components (transport lines) for which the risk of failure was determined, allowing the identification of transport lines most exposed to the risk of failure. The third and final stage of the method consisted of determining the reliability structure of the entire transport system by belt conveyors, taking into account the functions of individual elements (transport lines) in the system. The total risk calculated for the reliability structure determined in this way is the probability of not achieving the objective set for the transport system.
\end{abstract}

\section{Keywords}

risk, risk analysis and assessment, FMEA analysis, reliability structures. 


\section{Introduction}

Recently, there has been a clear increase in the interest of manufacturing enterprises in risk management due to the successive increase in the economic risk and the introduction of risk management to many management standards. An example here may be the ISO standards used in most manufacturing companies, such as ISO 9001, ISO 14001, ISO 45001, ISO /IEC 27001, ISO 23301, IATF 16949, ISO 22000, ISO 17025 and others, which includes aspects of risk management. The most recent ISO 9001:2015 standard contains an obligatory approach to risk management, which was not in the previous version of the 9001:2008 standard. The issue of risk management also appears in the context of risk assessment and reliability of machine systems and transport systems in mining (Andrejiova et al., 2015; 2020; Blazej\& Jurdziak, 2017;Blokus-Roszkowska \& Kolowrocki, 2015; Czaplicki, 2008; Czaplicki, 2009; Dhillon, 2017; Tworek et al. 2018). In copper ore mines having no market sales problems, any downtime in the transport system can lead to production losses that cannot be overcome at a later date. The lack of downtime also serves to minimize the unit costs of extraction, which are higher in underground mines than open-pit ones. Reducing production increases costs by making competition conditions even worse (Więcek et al., 2020). Downtime costs also increase the optimal cut-off grade (Kržanović et al., 2015), which reduces the resources that are profitable for extraction.

In general, the risk associated with an organizational or production system is the probability that the system will not perform the functions for which it was designed. The magnitude of the risk is, in turn, the difference between the defined and achieved goals of the production system resulting from the impact of the interfering factors (Aven, 2015; Simon et al., 2018; Więcek et al., 2019). Risk management is a systematic policy related to the implementation of procedures and practical action, aimed at bringing damage to a reasonable level. In other words, risk management boils down to reducing the degree of impact of risk factors on the functioning of an enterprise (Waters, 2002; Tworek et al., 2018). For this, however, it is necessary to quantify the size of the risk and use methods to assess it (Aabo et al., 2005). Mines collect data from automation systems on the states of the transport system; however, they are not used everywhere(Kuric et al., 2018).

Individual elements of the belt conveyor system may be subject to operational failures resulting in downtime at work and thus may significantly affect the achievement of the production objective. In many mines, there are catastrophic conveyor failures caused by factory defects, random overloads, or damage caused by impacts of large lumps of excavated material (Andriejova et al., 2020; Bajda et al., 2016). Damaged elements can be repaired or replaced with other elements (new or regenerated). Downtime may be shorter (several minutes as in the case of most electrical repairs) or longer (lasting several hours or changes as in the case of repair or replacement of elements such as gear or belt, depending on the type of failure). Therefore, the reliability of individual conveyor elements has a major impact on the reliability of the entire transport system and is reflected in the number of production losses (Czaplicki, 2014).

Some elements and components of belt conveyors are subject to a faster aging process, and for them, the intensity of failure increases quicker with age. These include gears, belt conveyors, and connections (Błażej et al., 2018). Due to a large number of elements in the entire transport system and the fact that after many years of operation, the system has elements of very different ages, there is no sense in averaging their properties. Therefore, in the case of different age of elements, it is allowed to describe the frequency of their damage by exponential distribution (Czaplicki, 2014). The exponential distribution can describe both the frequency of failure of individual components (Szymański, 2007) as well as complex machines such as excavators on wheels (Lazarević et al., 2018).

Monitoring, visual inspections, and NDT diagnostics are often introduced for the most expensive components and subassemblies. Systematic monitoring of the condition of gearboxes of belt conveyors working in very difficult conditions at hazardous production facilities enables not only detecting defects at an early stage but also to predict the development of defects. The introduction of the technique in the diagnosis system results in technical maintenance cost reductions (Antosz \& Ratnayake, 2019; Kuzin et al., 2019). Visual inspections and NDT diagnostics of expensive belts are also carried out (Błażej et al., 2018). The age and condition diagnosed affect individual decisions related to the continued use or preventive replacement (Kirjanów-Błażej et al., 2019). In the paper (Wodecki et al., 2017), authors presented the application of unsupervised learning method used for data classification in order to detect anomalies in diagnostic temperature signal from heavy-duty gearbox used in underground mining industry. The methodology is based on the Expectation-Maximization algorithm for Gaussian mixture model estimation, and parameterization with simple statistics. The technique applied to real data gives much better and more reliable results than direct one-dimensional time series analysis. The results obtained enabled detecting the unusual behavior of the gearbox.

The purpose of the article is to present and verify the concept of the method of reliable risk assessment based on the practical example. The developed method is based on the theory of reliability and reliability structure of complex objects, which in this case, is the belt conveyor transport system in one of the copper ore mines. The risk assessment takes into account the technical aspects of the analyzed object, according to which risk can be treated only in the category of loss, and not as in the case of economic systems in the category of 
profit or loss. The verification of the method was based on operational data collected over a period of 3 years on the failure of the belt conveyor system. From the point of view of this study, the belt conveyor transport system's risk management comes down to:

- Designation of elements of the belt conveyor system, the failure of which affects the transport system most, and thus the possibilities of delivering ore to mining shafts. This is especially important from the point of view of quickly aging or worn expensive components and subassemblies, which are not kept in the stock of spare parts or whose purchase time is lengthy.

- Determining the level of risk that is the probability of damage for individual belt conveyor transport lines.

- Determining the risk of failure of the entire system, taking into account its reliability structure, which has a significant impact on the reliability of the entire horizontal transport system.

The risk assessment of the analyzed belt conveyor system was carried out in three stages. In the first stage, the FMEA (Failure Mode and Effects Analysis) table was constructed, which enabled determining the risk for individual elements of the belt conveyor system. In the second stage, the risk of failure of individual transport lines included in the belt conveyor system was calculated. In the third stage, the reliability structure for the analyzed transport system was determined, and the total risk of the system was calculated. The advantage of the proposed method of reliable risk assessment is that in addition to the number of losses and the likelihood of their occurrence, it also takes into account the reliability structure of complex technical systems and objects, and not just like other methods proposed in the literature, the magnitude of the losses and the probability of their occurrence.The combination of the proposed methods allows us to quantify and assess the failure risk, taking into account its reliability structure for the entire transport system.

\section{Material and Methods}

\section{Review of the literature on the reliability of machine systems and transport systems in mining}

The main causes of damage, basic methods of reliability testing of propulsion systems, and a review of the propulsion systems of mining conveyors operating in 20 hard coal mines are presented in the paper (Szymański, 2007). Reliability indicators, calculated for a representative group of objects, were used to increase the times of trouble-free operations. Belt conveyors are driven by a system of one, two, or four drive motors, single or double speed. Mining conveyors are repairable objects according to the theory of reliability, while conveyor components belong to both classes of repairable and non-repairable facilities. According to the theory of reliability, an electric motor is an irreparable object, working with random gaps, and the operation of the system can be continued after replacing the engine. The research was carried out for data for the period 1995-1999. Data analysis showed that:

- In turbine clutch conveyors: $70 \%$ of the damage was caused by clutch failure, $20 \%$ - gear transmission failure, $8 \%$ - damaged drive motor, and in conveyor drives with a flexible clutch: $65 \%$ of the damage was caused by gear transmission failure, $20 \%$ - drive motor failure, $12 \%$ - clutch failure.

- The main causes of drive motor failure were: short circuit of stator winding - $80 \%$, bearing damage - $16 \%$. The main causes of turbine clutch failure were: loss of tightness - 70\%, damage to bearings - $25 \%$, while the most common damage to the gear transmission was: high-speed shaft $-70 \%$, bearings $-15 \%$, gears $-10 \%$ and loss of tightness - $4 \%$.

- In the motors tested, the following were most often damaged: rotor winding $52 \%$, stator winding - $18 \%$, bearing nodes $-15 \%$, and other $-15 \%$.

The introduction of a proactive monitoring system for mining machinery in open-pit mines enables the analysis of work processes and the state of units and components by reviewing the collected condition assessment parameters. This creates the opportunity to make rational decisions related to extending the service life. The obtained parameters form the basis for making decisions regarding the regeneration, reconstruction, or replacement of the unit and components, and also allows for developing guidelines for the design of these machines. One of the significant benefits of a proactive approach is the ability to update existing forecasting methods implemented in predictive programs. The compiled procedures enable the prediction of the behavior of the structure and potential failures, assessing the reliability of the structure under operating load(Lazarević et al., 2018; Tlach et al., 2017; Zajačko et al., 2018).

Used for aging objects (with increasing failure intensity over time), the exponential distribution can be used to describe catastrophic events that occur suddenly. The study (Bugaric et al., 2014) modeled the reliability of rubber belt conveyors used in the overburden stripping system at the Tamnava-East Field open cast mine using this type of distribution. The methodology used the fact that the working time of the belt until the damage can be represented by the composition of the exponential distribution (sudden damage) and normal distribution (damage developing gradually) and the existence of a linear relationship between the length of the belt and the average time of its operation until gradual damage. The proposed approach methodology and developed reliability 
function can be used to analyze the operation of other open-pit mines, with some adjustments, to ensure better downtime planning, backup conveyor belt planning, and to reduce the operational costs of the open-pit mine, for example, implementation of an optimal service strategy. This approach can also be used to calculate the cost of failure (Bugaric et al., 2012).

Preventive belt replacements are widely used in Poland due to their aging. Most often on the basis of age (recorded in the databases of PGE GiEK SA Turów and Bełchatów Branch) and cyclical visual inspections of the condition of belts on conveyors. Exchanges based on statistical data and distributions are not used. Currently, visual inspection is increasingly being replaced by diagnostic systems. This applies especially to steel ropes (type St), whose core state can be assessed by magnetic systems (for example, Błażej et al., 2018). A different approach was presented in the studies (Kolowrocki 2004; Blokus-Roszkowska \& Kolowrocki,2014; 2015; Blokus, 2020).

In the book (Kolowrocki, 2004), the author, taking into account the importance of security and efficiency of complex systems' operational processes, extended the two-state approach to the multi-state approach in analyzing their reliability. The assumption that systems consist of multi-state components whose reliability states degrade over time without repair allows for a more accurate analysis of their reliability, safety, and efficiency of operational processes. This assumption allowed him to distinguish the critical state for the reliability of the system, exceeding it is dangerous for the environment or not providing the necessary efficiency of the operational process. It has been found that an important feature of system reliability is the time until the critical state of the entire system's reliability is exceeded and its distribution, which is called the system's risk function. This distribution is closely related to the multi-state system reliability function, which is the basic feature of the multi-state system. For large systems, determining the exact reliability functions of complex systems and risk functions leads to very complex patterns that are often inconvenient for reliability practitioners. One important technique in this situation is the asymptotic approach to assessing system reliability. In this approach, instead of the preliminary complex formula for the system reliability function, after assuming that the number of system elements tends to infinity and finding the limit system reliability, its simplified form is obtained.

Mathematical methods used in the asymptotic approach to analyzing the reliability of complex systems are based on limiting assumptions on the distribution of ordinal statistics considered widely in the literature. These assumptions were used to develop the limit function of the reliability of systems composed of two- and multistate components.

More emphasis than ever before is placed on the belt conveyor's reliability that transports the extracted raw materials. In operation with a longwall system, up to $90 \%$ of extraction comes from one wall, which in turn must be efficiently operated by one receiving conveyor. That is why modern mines are looking for conveyors with reliability close to $100 \%$, and the machine industry is under increasing pressure to achieve this objective. This intention can be achieved by the machine-building industry by following the five design guidelines in Figure 1. (Hall et al., 2000; Kuric, 2011).

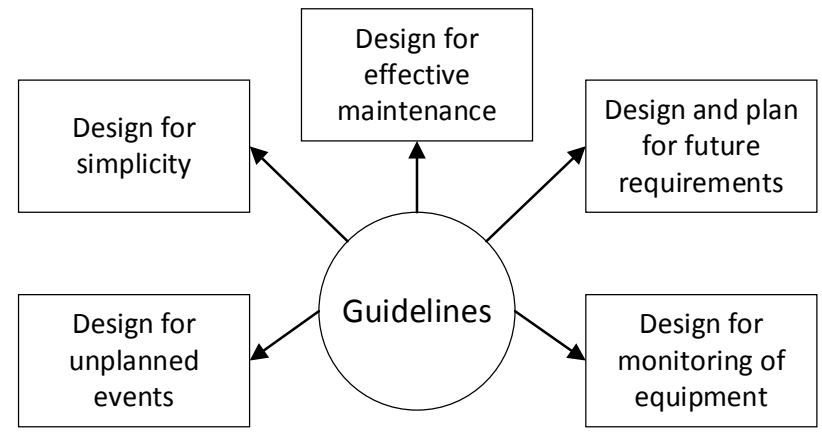

Fig. 1. Useful design-related guidelines for improving conveyor reliability (Dhillon, 2008)

In the studies (Ratnayake \& Antosz, 2017; Dhillon, 2008; Leugner, 1996; Chlebus et al., 2015) it was proposed to use the Total Productive Maintenance (TPM method) to eliminate losses that are considered to be the reasons for limiting the efficiency of devices (Figure 2).

The losses associated with machine system downtime described in the book (Dhillon, 2008) were caused by equipment failures and shutdowns of machines and control systems to replace machine tools/stamps from the production process. Damage losses related to the following two items:

- Reduced performance due to time and production loss problems from starting equipment to achieving a stable level of production.

- Defective production due to poor production quality, which causes discards and waste in the production process.

And also the losses related to the production speed regarding: 
- Performance reduction due to differences between design and actual speeds.

- Idle work and slight downtime due to incorrect sensor operation, causing machine shutdown or blocking of conveyors, dumps, etc.

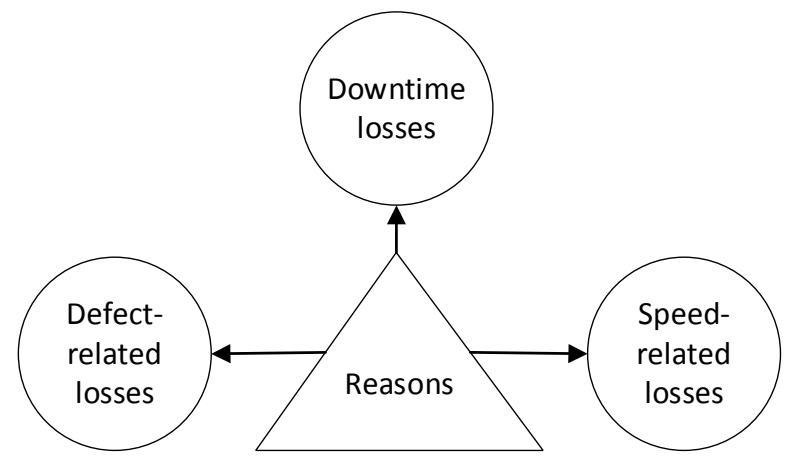

Fig. 2. Principal reasons for the performance of Total Productive Maintenance (TPM) (Dhillon, 2008).

In the 8th chapter (Reliability by Design. Reliability-Centered Maintenance) of the book (Campbell et al., 2016) James Picknell rightly stated that "since most failures are random, Reliability Centred Management (RCM) logic first asks if it is possible to detect the problem in time to keep the system running. If the answer is "yes", condition monitoring is needed. One must monitor often enough to detect deterioration, with enough time to act before the function is lost".

Of course, the knowledge of the age of the elements can and should be taken into account when choosing the frequency of inspections and indicating more endangered elements or choosing the moment of preventive replacement. Computer-aided systems for tape management are used for this, ERP system or other databases, or even Excel spreadsheets with information. Continuous and cyclical diagnostic systems that can build a knowledge base on the state of components (for example, belts) can also be helpful. However, it is sufficient to use the frequency of failure of individual elements and subassemblies in order to analyze and assess the risk of a conveyor belt transport system in a mine.

\section{The concept of a reliable risk assessment methods in production systems}

Reliability in the operational sense is most often defined as the probability that the system or its component will perform its tasks for which it was designed for a scheduled time under specific operating conditions (Aabo, 2005). However, risk can be defined as the probability of system losses due to risk factors. In the case of the analyzed mine, the risk will be understood as a failure to achieve the objective set out for the production system, i.e., not mining the appropriate size of copper ore assumed in the production plans $\mathrm{W}_{\text {plan }}$. The formulated concept of the risk assessment method is based on the assumption that risk $R$ as a probability of these losses being synonymous with unreliability $Z$, that is (Billinton \&Allan, 1992; Burduk, 2010; Burduk \& Chlebus, 2009):

$$
R(t)=Z(t)
$$

With this risk interpretation, the following formula for system reliability $N$ can be used (Bazovsky, 2004):

$$
N(t)+Z(t)=1 .
$$

Then the following equations should be accurate:

and

$$
N(t)+R(t)=1 .
$$

$$
R(t)=1-N(t) .
$$

The diversified level of reliability of individual elements of the production system means that the system's reliability as a whole will largely depend on the way its elements are connected, i.e., on the reliability structure. This means that different system reliability structures, built of the same number of identical, independent elements, result in different levels of system reliability. The system reliability structure's analysis should be preceded by the division of the system into individual components of the so-called system decomposition, reflecting logical connections in the system so that its individual parts are statistically independent and as large as possible. Depending on the type of element connections in the system, the most common are basic (series and parallel) and mixed (series-parallel and parallel-series) structures (Billinton \&Allan, 1992). In practice, systems with mixed structure will be most common: series-parallel and parallel-series. 
The system has a serial reliability structure if any element's failure causes the failure of the entire system. This definition means that the object is functional if and only if all its elements are functional and that as the number of system elements increases, its reliability decreases. The reliability $N_{S}$ of the system with a serial structure is determined by the formula (Billinton \&Allan, 1992):

$$
N_{S}=N_{1} \cdot N_{2} \cdot \ldots \cdot N_{n}=\prod_{i=1}^{n} N_{i}
$$

where $N_{1}, N_{2}, \ldots, N_{n}$ are the reliabilities of individual system components.

Using the formula (4), the total risk $R_{C}$ of the system with serial structure can be determined by:

$$
R_{C}=1-\left[\left(1-R_{1}\right) \cdot\left(1-R_{2}\right) \cdot \ldots \cdot\left(1-R_{n}\right)\right]
$$

where $R_{1}, R_{2}, \ldots, R_{n}$ are the risks of individual elements of the system.

A system with a parallel reliability structure is exploitable if at least one of its components is fit. The parallel structure is characteristic of systems in which the elements perform the same task. The reliability of such a system will increase as the number of system components increases and is determined by the formula (Billinton \&Allan, 1992):

$$
N_{S}=1-\left[\left(1-N_{1}\right) \cdot\left(1-N_{2}\right) \cdot \ldots \cdot\left(1-N_{n}\right)\right]=1-\prod_{i=1}^{n}\left(1-N_{i}\right),
$$

where $N_{1}, N_{2}, \ldots, N_{n}$ are the reliabilities of individual system components.

The total risk $R_{c}$ of systems with a parallel structure can be determined based on the formula:

$$
R_{c}=R_{1} \cdot R_{2} \cdot \ldots \cdot R_{n}=\prod_{i=1}^{n} R_{i}
$$

where $R_{1}, R_{2}, \ldots, R_{n}$ are the risks of individual areas/elements of the system.

In practice, production systems with a parallel reliability structure defined in this way do not occur or are very rare, as the excess of elements (for example, machines, employees, means of transport, etc.) means unused resources, which increases production costs (Aabo, 2005; Burduk \& Krenczyk, 2017; Burduk \& Chlebus, 2009; Więcek \& Więcek, 2017). Risk determination for parallel production structures is much more appropriate in this case. An example of such a structure is shown in Figure 3.

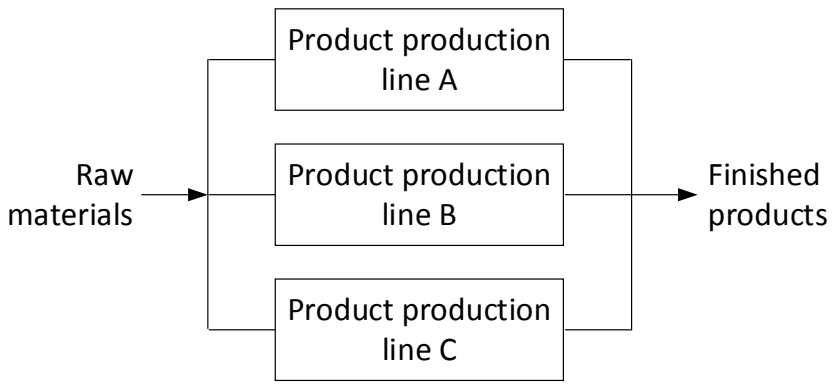

Fig. 3. An example of a parallel production structure

Treating the system structure from Figure 3 as a parallel production structure, and taking into account the nature and specificity of production systems, the risk formula considers the system weights should be according to formula 9 .

Weights are assigned depending on the line's capacity and show how each line has an impact on total risk. These lines work independently of each other and supply the output in varying degrees:

$$
R_{S C}=\alpha_{1} R_{1}+\alpha_{2} R_{2}+\cdots+\alpha_{n} R_{n} \text {, where } \alpha_{1}+\alpha_{2}+\cdots+\alpha_{n}=1, \alpha_{1}, \ldots, \alpha_{n} \geq 0 \text {. }
$$

The concept of risk interpretation proposed in the method presented above as a synonym of unreliability allows for identification of elements of the production system most exposed to the impact of risk factors or elements in which the impact of risk factors will most transform into the functioning of the entire production system. Of course, real production systems most often have serial-parallel and parallel-serial structures. Thus, 
the above-mentioned basic structures should be modified to suit the needs of the risk assessment of the analyzed system.

\section{Application of the FMEA method to risk assessment}

The analysis of the causes and effects of FMEA (Failure Mode and Effects Analysis) defects was used to assess the risk of failure of individual elements of belt conveyors. The method belongs to the group of quality management methods and is included in the standard ISO 9001 and ISO 31000. The use of the method allows, among others, to identify the area in the process where the risk is greatest (Burduk \& Krenczyk, 2017; Ferencz et al. 2015). The size of the failure risk for a given element expressed by RPN (Risk Priority Number) is determined based on indicators whose values are estimated on the basis of knowledge and experience of persons participating in the assessment.

A special form was developed in which the following information was entered to conduct FMEA analysis of the failure of belt conveyors in the analyzed mine:

- potential defects for individual elements included in the construction of the belt conveyor,

- the probability of their occurrence $(\mathrm{P})$,

- the degree of hazard $(\mathrm{Z})$, determining the magnitude of the effects that arise as a result of the appearance of a defect during the production process and the use of the product,

- traceability $(\mathrm{T})$, determining the possibility of detecting that a potential defect or its cause will become apparent later.

In the next step, numerical values were given to individual parameters (Wolfgang \& Klaus, 2007). Values, according to the scale shown in Figure 4, were given by employees who are responsible for the efficiency of belt conveyors on a daily basis (Table 4).

\begin{tabular}{|c|c|c|c|c|c|c|c|c|c|c|c|}
\hline \multicolumn{2}{|l|}{ Indicator } & 1 & 2 & 3 & 4 & 5 & 6 & 7 & 8 & 9 & 10 \\
\hline Level of hazard & $\mathbf{Z}$ & & & & & $i m$ & ri & & & & \\
\hline Probability & $\mathbf{P}$ & & & & & ima & ris & & & & \\
\hline Detection & $\mathbf{T}$ & & & & & ima & ri & & & & \\
\hline
\end{tabular}

Fig. 4. The scale and magnitude of risk parameters (Burduk \& Krenczyk, 2017)

Next, the risk value was determined for individual elements of belt conveyor system construction according to the formula:

$$
R P N=(Z) \cdot(P) \cdot(T)
$$

Calculating the $R P N$ allows the assessment of the risk of damage to individual elements included in the construction of the belt conveyor, and thus indicates the element most vulnerable.

\section{Characteristics of the transport system}

The analyzed mining plant, which verified the proposed risk assessment method, is one of the three plants of the largest copper and silver producers in the world. The mining area and area of the plant is $176 \mathrm{~km}^{2}$ and is located in the southwestern part of Poland. The mine exploits copper-bearing sandstones, tar-shale (copperbearing), and carbonate copper ore (calcite-dolomitic layers), from which copper and silver are obtained. In addition, rock salt is mined in one of the mines as an accompanying mineral from higher deposits. In a part of the "Sieroszowice" mining area, above the copper ore deposit, at a distance of 80-100 meters, a rock salt deposit has been documented, having the character of a seam with a thickness ranging from 40 to 150 meters, from which over 300 thousand tons of rock salt is extracted annually intended for the domestic market (Bartlett et al., 2013).

The ore is transported to glass wells located in the vicinity of the mining shafts by means of a belt conveyor system (departmental and collective). There are three mining shafts operating in the mine: SI (two skips with a capacity of $18 \mathrm{Mg}$ ), SII (four skips with a capacity of $30 \mathrm{Mg}$ ), and SIII (two skips with a capacity of $18 \mathrm{Mg}$ ). Figure 5 shows a diagram of belt conveyors in the mine, mining areas, storage reservoirs, and mining shafts in one of the underground copper ore mines.

The length of the conveyor transport system at the mine is over $30 \mathrm{~km}$ and is divided into two subsystems:

1. departmental transport, which is the initial phase of hauling spoil from discharge points (grates) located in the areas of mining divisions for main haulage conveyors, 
2. main transport, the purpose of which is to collect spoil from departmental conveyors and transport it towards the mining shafts.

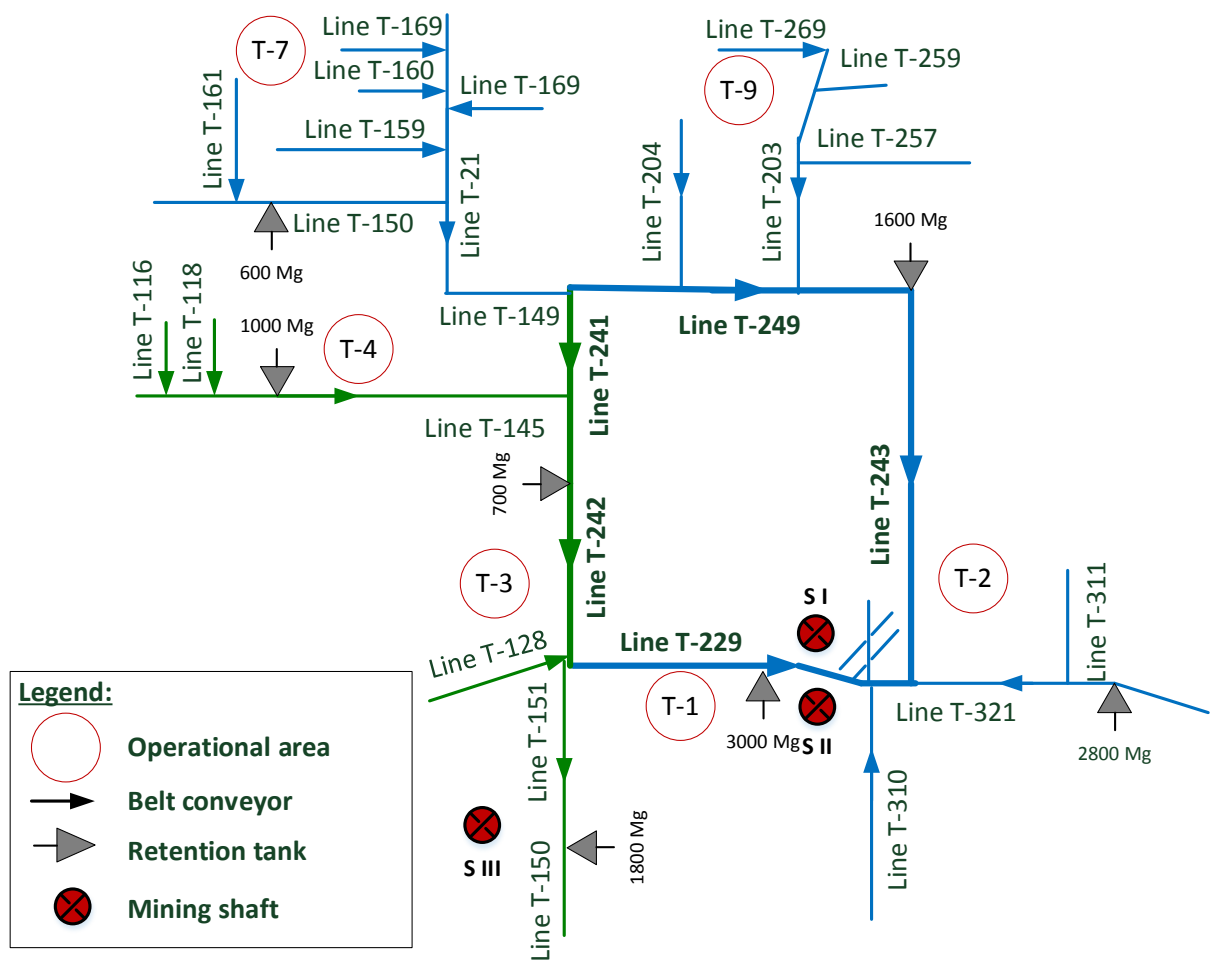

Fig. 5. Map of belt conveyors, storage reservoirs, mining fields, and mine shafts (Koman and Laska, 2014).

From the point of view of reliability, the conveyor system in the mine creates a multi-branch serial structure, in which each branch consists of departmental conveyors having several loading points (grates) (at the beginning and on the route) that can feed spoil to the next conveyor in series or ore on the collecting conveyor from another branch. Collective conveyors can be fed with ore through grilles or loading from other conveyors. The system becomes a parallel-series system due to the arrangement of main conveyors in the so-called "Square" (Figure 5), because the ore from the faces to the shafts travels in a series of departmental and collective conveyors, and after reaching the "square" it has the opportunity to reach the shaft tanks by three main conveyor routes, which ensures parallel arrangement of conveyors and the possibility of their reversion. However, a single conveyor will be treated as a serial system, because it consists of many elements cooperating in such a way that the failure of any of them stops the conveyor and all preceding it.

The basic elements that make up the construction of the conveyor belt and associated devices are:

- head station (drive) of the drum/drums or,

- the drive system (engines, clutches, and gears),

- power supply and automation system,

- a closed-loop of belts consisting of sections and connections (vulcanized, glued or mechanical),

- tensioning system;

and repeatable segments of the route structure with:

- upper and lower idler sets,

- turning station with drum,

- $\quad$ loading and unloading devices, which include a grille, hoppers and dispenser nozzles,

- retention tanks with loading and unloading system.

Despite the huge financial outlays incurred in this area, all components of the conveyor are highly exposed to failures. After many years of operation, the system contains elements of very different ages, and there are thousands of them. For example, there are almost $60 \mathrm{~km}$ of tape in the analyzed mine (which consists of several thousand sections and the same number of connections), there are hundreds of thousands of pulleys, several dozen gears, etc. The whole system and individual elements have their own specificity and averaged properties. In fact, individual damages are rare, and the destruction of even such elements as gears may soon intensify wear or cause damage to other parts of the conveyor. Even the shortest unplanned downtime, in this case, is associated with losses, not to mention the cost of buying new components (Bartlett et al., 2013). 


\section{Results and Discussion}

\section{Data analysis on belt conveyor system failure}

The exploitation process in the analyzed mine takes place in a 4-shift system ( 24 hours a day) from Monday to Friday. During each day of work, there are 2 breaks related to blasting works at 6.00 and 18.00 (plus waiting time after blasting works). The spoil transport process takes place at the same time as the exploitation process, with the difference that it is shorter by the time of transporting people operating conveyor belts to the workplace. Depending on the conveyor location, this time is approximate, from 240 to 270 minutes of operation of the glazing and main haulage conveyors and from 180 minutes to 240 minutes for departmental conveyors.

Data from a 36-month (3-year) period were used for the risk analysis, derived from the dispatcher's database of the horizontal transport department. The data set contained almost 3,000 records about the stoppages of the conveyor system in the mine. Each record contained information such as the name of the conveyor, date of failure, shift number, stop time, the reason for failure divided into categories (for example, mechanical, electrical, other), description of the failure, the department responsible for repairing the failure and impact on mining. Only failures that affected the volume of production (2,511 records) were taken for further analysis. The first analysis that was made was a breakdown of failure durations in individual years (Table 1).

Tab.1. Summary of the number and duration of conveyor failure

\begin{tabular}{c|c|c|c|c|c}
\hline Year & $\begin{array}{c}\text { Number of } \\
\text { stoppages }\end{array}$ & $\begin{array}{c}\text { The average duration of } \\
\text { stoppage[min] }\end{array}$ & $\begin{array}{c}\text { Standard } \\
\text { deviation }\end{array}$ & $\begin{array}{c}\text { Minimal duration } \\
\text { [min] }\end{array}$ & $\begin{array}{c}\text { Maximum duration } \\
\text { [min] }\end{array}$ \\
\hline$I$ & 643 & 46 & 58 & 8 & 801 \\
$I I$ & 786 & 52 & 62 & 8 & 860 \\
$I I I$ & $1082(2511)$ & 45 & 53 & 5 & 595
\end{tabular}

The analysis of the collected data shows that the average failure time is generally about 47 minutes and ranges from 5 minutes to 860 minutes. Attention should be drawn to the increase in the number of failures in subsequent years. A more detailed analysis of the data showed that most failures occur in the range of 5 to 240 minutes (these are faults removed during 1 work shift), while the fewer failures were lasting from 240 minutes to 860 minutes (these failures last longer than 1 work shift).

Another analysis of this data concerned the division of causes of failures into 3 main groups: electrical (E), mechanical (M), other (I). Table 2 presents the results of failures by a group of causes.

Tab.2. Number and duration of breakdowns by a group of causes

\begin{tabular}{c|c|c|c|c}
\hline Type of failure & $\begin{array}{c}\text { Number of } \\
\text { stoppages }\end{array}$ & $\begin{array}{c}\text { The average duration of } \\
\text { stoppage [min] }\end{array}$ & $\begin{array}{c}\text { Minimal duration } \\
\text { [min] }\end{array}$ & $\begin{array}{c}\text { Maximum duration } \\
\text { [min] }\end{array}$ \\
\hline E & 1749 & 42 & 5 & 680 \\
M & 443 & 62 & 860 & 5 \\
I & 319 & 53 & 895
\end{tabular}

As it results from the analysis of the data from Table 2, most failure is caused by an electric cause, and the average conveyor downtime is the shortest. A more detailed breakdown of the type of failure, taking into account the type of the conveyor belt element, to which the failure relates, is presented in Table 3 . In addition, the analysis included failures related to the power supply of the belt conveyor.

Tab.3. Division of failures into types and components of the belt conveyor

\begin{tabular}{|c|c|c|c|c|c|}
\hline Damaged object & $\begin{array}{l}\text { Type of } \\
\text { failure }\end{array}$ & $\begin{array}{l}\text { Number of } \\
\text { stoppages }\end{array}$ & $\begin{array}{c}\text { The average duration } \\
\text { of stoppage [min] }\end{array}$ & $\begin{array}{c}\text { Minimal duration } \\
\text { [min] }\end{array}$ & $\begin{array}{c}\text { Maximum } \\
\text { duration [min] }\end{array}$ \\
\hline \multirow{3}{*}{ Supply system } & $\mathrm{E}$ & 926 & 65.5 & 12 & 680 \\
\hline & M & 11 & 26.9 & 15 & 45 \\
\hline & $\mathrm{I}$ & 18 & 35.3 & 30 & 88 \\
\hline \multirow{3}{*}{ Belt } & $\mathrm{E}$ & 0 & 0 & 0 & 0 \\
\hline & M & 106 & 85.1 & 21.5 & 450 \\
\hline & $\mathrm{I}$ & 6 & 28.5 & 20 & 70 \\
\hline \multirow{3}{*}{ Roller sets } & $\mathrm{E}$ & 0 & 0 & 0 & 0 \\
\hline & M & 89 & 55.8 & 12 & 412 \\
\hline & $\mathrm{I}$ & 2 & 73.5 & 20 & 127 \\
\hline \multirow{3}{*}{$\begin{array}{l}\text { The head station } \\
\text { (Transmission) }\end{array}$} & $\mathrm{E}$ & 544 & 65.1 & 5 & 417.5 \\
\hline & M & 39 & 64.2 & 18.8 & 135 \\
\hline & $\mathrm{I}$ & 15 & 51.7 & 22 & 112 \\
\hline \multirow{3}{*}{ Turning station } & $\mathrm{E}$ & 41 & 27.9 & 26 & 30 \\
\hline & M & 14 & 130.3 & 25 & 186 \\
\hline & $\mathrm{I}$ & 1 & 26.0 & 26 & 26 \\
\hline \multirow{3}{*}{$\begin{array}{c}\text { Equipment } \\
\text { Loading / Unloading }\end{array}$} & $\mathrm{E}$ & 171 & 46.2 & 15 & 360 \\
\hline & M & 295 & 58.5 & 15 & 860 \\
\hline & I & 233 & 89.6 & 30 & 595 \\
\hline
\end{tabular}


Risk assessment of the failure of individual elements of belt conveyors

The FMEA table was constructed, which enabled determining the RPN for individual elements of the belt conveyor system. The RPN value is between 1 and 1000. The high RPN value is the equivalent of high risk in the process. In the case of increased RPN value, the team of employees should make efforts to reduce risk, using corrective action. An expert team of maintenance staff decided that RPN values below 100 would be considered an acceptable risk. In the case of an RPN value above 100, corrective action leading to the reduction of the risk level to an acceptable value will be further developed. Table 4 presents the results of the expert team's work in the form of a developed FMEA table based on data on the frequency of non-compliance in the considered process and their effects and causes.

Tab.4. FMEA form with the calculated RPN for the belt conveyor transport system

\begin{tabular}{|c|c|c|c|c|c|}
\hline $\begin{array}{l}\text { The element of } \\
\text { the belt conveyor }\end{array}$ & Potential fault / defect & $\begin{array}{l}\text { Probability of } \\
\text { occurrence (P) } \\
\text { [pts.] }\end{array}$ & $\begin{array}{c}\text { Degree of danger } \\
(Z) \\
\text { [pts.] }\end{array}$ & $\begin{array}{c}\text { Traceability } \\
\text { (T) } \\
\text { [pts.] }\end{array}$ & $\begin{array}{l}\text { RPN } \\
\text { [pts.] }\end{array}$ \\
\hline \multirow{4}{*}{ Supply system } & no voltage & 9 & 10 & 2 & 180 \\
\hline & low voltage & 8 & 8 & 3 & 192 \\
\hline & overload & 9 & 10 & 5 & 450 \\
\hline & optical fiber failure & 6 & 9 & 4 & 216 \\
\hline \multirow{6}{*}{ Belt } & belt speed sensor failure & 4 & 6 & 3 & 72 \\
\hline & failure of the belt tensioning system & 4 & 6 & 4 & 96 \\
\hline & failure of the rim & 6 & 5 & 4 & 120 \\
\hline & belt rip & 5 & 5 & 4 & 100 \\
\hline & belt tear & 4 & 10 & 2 & 80 \\
\hline & belt converging & 5 & 10 & 6 & 300 \\
\hline \multirow{3}{*}{ Roller sets } & damage to the roller & 9 & 4 & 7 & 252 \\
\hline & roller wear & 8 & 4 & 9 & 288 \\
\hline & no roller & 7 & 5 & 6 & 210 \\
\hline \multirow{5}{*}{$\begin{array}{l}\text { The head station } \\
\text { (Transmission) }\end{array}$} & drives not ready & 10 & 8 & 4 & 320 \\
\hline & system failure & 7 & 10 & 2 & 140 \\
\hline & failure of the drive drum & 8 & 10 & 4 & 320 \\
\hline & activation of safety sensors & 7 & 9 & 1 & 63 \\
\hline & overload & 7 & 9 & 3 & 189 \\
\hline \multirow{3}{*}{ Turning station } & control system failure & 6 & 9 & 3 & 162 \\
\hline & backfilling the excavated material (spoil) & 7 & 8 & 2 & 112 \\
\hline & the outflow of spoil from tanks/dispensers & 8 & 8 & 2 & 128 \\
\hline \multirow{8}{*}{$\begin{array}{l}\text { Loading/unloading } \\
\text { device }\end{array}$} & dispenser failure & 6 & 10 & 5 & 300 \\
\hline & blockade of the dispenser nozzle & 8 & 6 & 2 & 96 \\
\hline & no dispenser control & 7 & 8 & 6 & 336 \\
\hline & blocked stone & 8 & 9 & 4 & 288 \\
\hline & failure of the hydraulic hammer & 8 & 6 & 1 & 48 \\
\hline & no control of the hydraulic hammer & 2 & 6 & 2 & 24 \\
\hline & mud-covered conveyor route under the grille & 3 & 10 & 2 & 60 \\
\hline & tank overflow & 8 & 9 & 2 & 144 \\
\hline
\end{tabular}

The maximum $R P N$ value of the analyzed system is 29,000 (29 faults of 1,000 points each). Thus, the value of losses due to the risk of belt conveyor failure for this transport system is:

$$
R S=\frac{5286}{29000}=0.182
$$

The use of FMEA does not allow to identify the risk size of the entire transport system. Value $R S=0.182$ is the average value of the risk of loss of structural components of one belt conveyor that is affected by:

- the probability of failure of individual conveyor elements,

- the magnitude of the threat to the transport process caused by the failure of these elements,

- the traceability.

According to the FMEA analysis, the risk and overloading of the supply system and the risk of drive drum failure are the most significant risks and the most impacting on the transport system. However, in accordance with the principles of the FMEA method, corrective actions should be taken for all elements for which the $R P N$ value is higher than 100 . Only 9 out of 29 cases in the table reach the limit values in the method, i.e., less than 100 of the coefficients of RPN of the FMEA table. The FMEA method allows us to identify the system elements most exposed to the impact of risk factors or whose trouble-free operation affects most strongly the functioning of the entire system. An important element of the transport system's overall risk is the cost risk that incurs specific costs of the enterprise (so-called risk costs) - incurring additional prevention costs for the most critical elements by introducing changes to transport processes that improve system reliability. If the cause of the failure cannot be eliminated, costs should be incurred to increase the detection of this failure or reduce the negative effects of their occurrence regarding the transport process or the production process. This method also impacts 
the cost of non-compliance that may occur, paying attention to the most emergency elements and their impact on the effects during the production process and the possibility of their detection. The next item will review the concept of a reliable risk assessment method.

\section{Verification of the reliable risk assessment method for a horizontal copper ore transport system}

There are 3 mining shafts in the analyzed mine: SI, SII, and SIII. The production volume of the entire mine depends on their production capacity. The production capacity of the mine $W_{\text {plan }}$ is $16,000,000$ tonnes of copper ore per year and 55,900 tonnes per day. The production capacity for individual mining shafts /subsystems is summarized in Table 5.

Tab.5. Summary of shafts and lines extraction capacity

\begin{tabular}{c|c}
\hline $\begin{array}{c}\text { Shaft mining capacity } \\
\text { [tons of copper ore/day] }\end{array}$ & $\begin{array}{c}\text { Line mining capacity (subsystems) } \\
\text { [tonsof copper ore/day] }\end{array}$ \\
\hline $\boldsymbol{W}_{\text {plansI }}=8,300$ & $S_{I, I}^{1}=19,600$ \\
$\boldsymbol{W}_{\text {plansII }}=39,000$ & $S_{I, I I}^{2}=27,700$ \\
$\boldsymbol{W}_{\text {planSIII }}=8,600$ & $S_{I I I}=8,600$
\end{tabular}

Mining extraction shafts SI and SII are located very close to each other and supplied by the same systems of belt conveyors transporting copper ore from mining fields: T-1, T-2, T-7, T-9, and through the belt conveyor lines of the main haulage square T-229, T-243, T-249, and T-321. Mining shaft SIII is supplied by departmental conveyors from T-3 and T-4 mining fields and by T-241, T-242, and T-151 lines of the haulage square. In view of the adopted assumptions, the conveyor transport system in the analyzed mine will have a parallel-series structure shown in Figure 6, in which 3 lines stand out (subsystems) $S_{I, I I}^{1}, S_{I, I I}^{2}, S_{I I I}$.

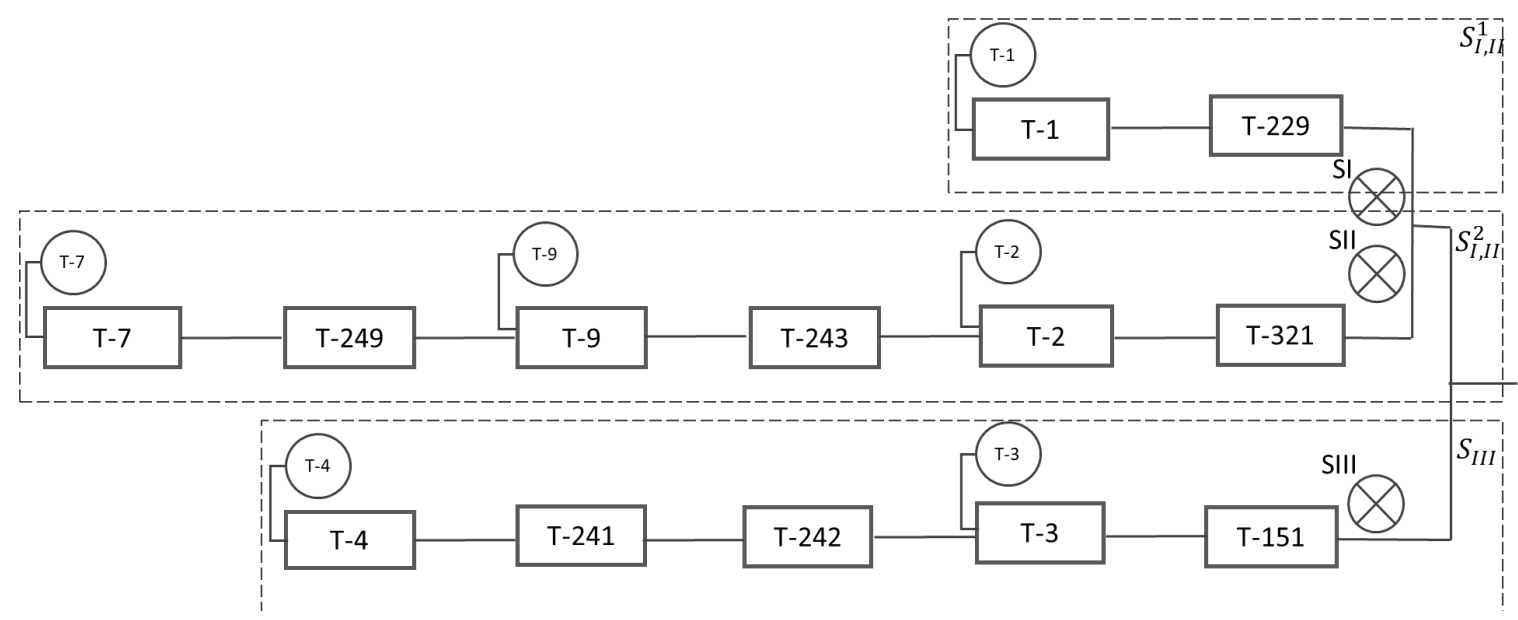

Fig. 6. Series-parallel structure of the belt conveyor transport system

Weights should be assigned to individual elements for the presented parallel-serial structure of the analyzed transport system $\alpha_{\mathrm{s}_{I, I I}^{1}}, \alpha_{\mathrm{s}_{\mathrm{I}, I I}^{2}}, \alpha_{\mathrm{s}_{\text {III }}}$ corresponding to the daily production capacity of the line. It is assumed that the system components work independently of each other, i.e., a failure of one line does not cause a break in the functioning of the other lines.

Considering first the parallel structure of the analyzed transport system and denoting by $\mathrm{Rs}_{\mathrm{I}, \mathrm{II}}^{1}$ risk of line $\mathrm{S}_{\mathrm{I}, \mathrm{II}}^{1}$ (Fig. 6), by $\mathrm{Rs}_{\mathrm{I}, \mathrm{II}}^{2}$ risk of line $\mathrm{S}_{\mathrm{I}, \mathrm{II}}^{2}$, and by $\mathrm{Rs}_{\mathrm{III}}$ risk of line $\mathrm{S}_{\mathrm{III}}$, a formula for the total risk of the system $\mathrm{R}_{\mathrm{SC}}$ has the form:

where

$$
R_{S C}=\alpha_{s_{I, I I}^{1}} R s_{I, I I}^{1}+\alpha_{s_{I, I I}^{2}} R s_{I, I I}^{2}+\alpha_{s_{I I I}} R s_{I I I}
$$

$$
\alpha_{\mathrm{s}_{\mathrm{I}, \mathrm{II}}^{1}}+\alpha_{\mathrm{s}_{\mathrm{I}, \mathrm{II}}^{2}}+\alpha_{\mathrm{s}_{\mathrm{III}}}=1
$$

Weights were determined based on daily extraction (Table 5): $\alpha_{\mathrm{s}_{\mathrm{I}, \mathrm{II}}}=0.3506 ; \alpha_{\mathrm{S}_{\mathrm{I}, \mathrm{II}}^{2}}=0.4955 ; \alpha_{\mathrm{s}_{\mathrm{III}}}=$ 0.1538. Substituting these values to formula (11) we obtain:

$$
R_{S C}=0.3506 \cdot R s_{I, I I}^{1}+0.4955 \cdot R s_{I, I I}^{2}+0.1538 \cdot R s_{I I I} \cdot
$$


The risk of the parallel system's individual components is calculated from the formula for the risk of a serial system. Based on Fig. 6, the risks of individual lines take the form:

$$
\begin{gathered}
R s_{I, I I}^{1}=1-\left(1-R_{T-1}\right)\left(1-R_{T-229}\right)=1-(1-0.182)(1-0.182)=0.331 \\
\mathrm{Rs}_{\mathrm{I}, \mathrm{II}}^{2}=1-\left(1-\mathrm{R}_{\mathrm{T}-7}\right)\left(1-\mathrm{R}_{\mathrm{T}-249}\right)\left(1-\mathrm{R}_{\mathrm{T}-9}\right)\left(1-\mathrm{R}_{\mathrm{T}-243}\right)\left(1-\mathrm{R}_{\mathrm{T}-2}\right)\left(1-\mathrm{R}_{\mathrm{T}-321}\right) \\
=1-(1-0.182)(1-0.182)(1-0.182)(1-0.182)(1-0.182)(1-0.182)=0.7 \\
R s_{I I I}=1-\left(1-R_{T-4}\right)\left(1-R_{T-241}\right)\left(1-R_{T-242}\right)\left(1-R_{T-3}\right)\left(1-R_{T-151}\right) \\
=1-(1-0.182)(1-0.182)(1-0.182)(1-0.182)(1-0.182)=0.634 .
\end{gathered}
$$

As can be seen, the risks of all transport lines are very high. The probability of an unfulfilled target is greatest for the line $\mathrm{Rs}_{\mathrm{I}, \mathrm{II}}^{2}$ and amounts to $70 \%$, while for lines $\mathrm{Rs}_{\mathrm{III}} 63 \%$, and for lines $\mathrm{Rs}_{\mathrm{I}, \mathrm{II}}^{1} 33 \%$. These risk levels are unacceptable because the likelihood of failure to meet the production target set for the transport system is too high. The presented risk amounts confirm the need to introduce measures to reduce it. In the next step, the risk was determined for the entire transport system.

Substituting the risks of individual lines to the total risk formula we obtain:

$$
\begin{gathered}
R_{S C}=0.3506\left(1-\left(1-R_{T-1}\right)\left(1-R_{T-229}\right)\right)+ \\
0.4955\left(1-\left(1-R_{T-7}\right)\left(1-R_{T-249}\right)\left(1-R_{T-9}\right)\left(1-R_{T-243}\right)\left(1-R_{T-2}\right)\left(1-R_{T-321}\right)\right)+ \\
0.1538\left(1-\left(1-\mathrm{R}_{\mathrm{T}-4}\right)\left(1-\mathrm{R}_{\mathrm{T}-241}\right)\left(1-\mathrm{R}_{\mathrm{T}-242}\right)\left(1-\mathrm{R}_{\mathrm{T}-3}\right)\left(1-\mathrm{R}_{\mathrm{T}-151}\right)\right) .
\end{gathered}
$$

Having determined the risk of failure of elements of a single conveyor belt $\mathrm{R}_{\mathrm{T}_{\mathrm{i}}}=0.182$ and assuming it is the same for all conveyors, the total risk $\mathrm{R}_{\mathrm{SC}}$ for the entire system can be calculated as follows:

$$
\begin{gathered}
R_{S C}=0.3506(1-(1-0.182)(1-0.182))+ \\
0.4955(1-(1-0.182)(1-0.182)(1-0.182)(1-0.182)(1-0.182)(1-0.182))+ \\
0.1538(1-(1-0.182)(1-0.182)(1-0.182)(1-0.182)(1-0.182)) \\
=0.1160+0.3471+0.0975=0.5606 .
\end{gathered}
$$

The total risk of the transport system calculated in this way means that with a probability of $56.06 \%$, the objective set for the production system (extraction of 16,000,000 tonnes of copper ore per year or 55,900 tonnes per day) will not be carried out.

The obtained results confirm the actual data on the failure and conversations with employees of the mine maintenance department. One of the practical conclusions of the method used is to indicate the belt conveyor's structural elements most vulnerable to failures and the transport lines with the greatest risk of failure. The proposed method allows determining the risk for the entire transport system, taking into account its reliability structure.

\section{Conclusions and Further research}

Nowadays, companies wanting to gain a competitive advantage are looking to improve the efficiency of their processes in various areas. One of them is the analysis, assessment, and then elimination of the risk constantly present in production systems. The introduction of risk management is increasingly seen by manufacturing companies as one of the ways to improve production efficiency. This article proposes and verifies a practical method for the reliability of risk assessment. The method allows the risk assessment of complex technical systems, which is the belt conveyor transport system.

The method was verified using data on the construction of belt conveyors, functions of individual transport lines, and detailed operational data on the failure and standstill of the conveyor for three years. Risk factors were identified, and their occurrence characteristics determined based on these data. For this purpose, the failures were divided into types for which repair times were analyzed.

The risk assessment of the belt conveyor system was carried out in three stages. In the first stage, the structural elements with the greatest impact on its failure rate were determined using the FMEA method. In the second stage, transport lines with the highest risk of failure were identified. At the third stage, the risk of the entire transport system by transport conveyors was determined, taking into account its reliability structure.As a result, it is also possible to quickly determine the number and type of corrective actions leading to a reduction in the level of acceptable risk for the entire system. 
The calculations presented above show that the risk of belt conveyors' failure is very high. However, the analysis did not take into account shaft tanks' occurrence that compensates for the losses associated with the risk of conveyor failure.

\section{References}

Aabo, T., Fraser, J.R.S., \& Simkins, B.J. (2005). The rise and transformation of the chief risk officer: A success story on enterprise risk management. Journal of Applied Corporate Finance, 17(3), 8-18.

Andrejiova, M., Grincova, A., \& Marasova, D. (2020). Monitoring dynamic loading of conveyer belts by measuring local peak impact forces. Measurement, 158, 107690, https://doi.org/10.1016/j.measurement.2020.107690

Andrejiova, M., Grincova, A., Marasova, D., \& Grendel, P. (2015). Multicriterial assessment of the raw material transport. Acta Montanistica Slovaca, 20(1), 26-32.

Antosz, K., \& Ratnayake, R. C. (2019). Spare parts' criticality assessment and prioritization for enhancing manufacturing systems' availability and reliability. Journal of Manufacturing Systems, 50, 212-225, https://doi.org/10.1016/j.jmsy.2019.01.003

Aven, T. (2015). Risk analysis. Chichester, West Sussex: Wiley Blackwell.

Bazovsky, I. (2004). Reliability theory and practice. Courier Corporation.

Bajda, M., Błażej, R., \& Jurdziak, L. (2016). A new tool in belts resistance to puncture research. Mining Science, 23, 173-182, DOI: $10.5277 / \mathrm{msc} 162314$

Bartlett, S. C., Burgess, H., Damjanović, B., Gowans, R. M., \& Lattanzi, C. R. (2013). Technical report on the copper-silver production operations of KGHM Polska Miedź SA in the Legnica-Głogów copper belt area of southwestern Poland. MICON report.

Billinton, R., \& Allan, R. N. (1992).Reliability evaluation of engineering systems. New York: Plenum press.

Blazej, R., \& Jurdziak, L. (2017). Condition-based conveyor belt replacement strategy in lignite mines with random belt deterioration. In IOP Conference Series: Earth and Environmental Science (Vol. 95, No. 4, p. 042051). IOP Publishing, https://doi.org/10.1088/1755-1315/95/4/042051

Błażej, R., Jurdziak, L., Kozłowski, T., \& Kirjanów, A. (2018). The use of magnetic sensors in monitoring the condition of the core in steel cord conveyor belts-tests of the measuring probe and the design of the DiagBelt system. Measurement, 123, 48-53, https://doi.org/10.1016/j.measurement.2018.03.051

Blokus, A. (2020). Multistate System Reliability with Dependencies. Academic Press.

Blokus-Roszkowska, A., \& Kolowrocki, K. (2014). Failure dependency analysis of series system with example of conveyor belt. The 10th International Conference on Digital Technologies 2014(pp. 290-297). IEEE, doi: 10.1109/DT.2014.6868730

Blokus-Roszkowska, A., \& Kołowrocki, K. (2015). Reliability analysis of conveyor belt with dependent components. Safety and Reliability of Complex Engineered Systems, 1127-1136.

Bugaric, U., Tanasijevic, M., Polo Vina, D., Ignjatovic, D., \& Jovancic, P. (2012). Lost production costs of the overburden excavation system caused by rubber belt failure. Eksploatacja i Niezawodność, 14, 333-341.

Bugarić, U., Tanasijević, M., Polovina, D., Ignjatović, D., \& Jovančić, P. (2014). Reliability of rubber conveyor belts as a part of the overburden removal systecase study: Tamnava -east field open cast mine. Technical Gazette, 21(5), 925-932.

Burduk, A., \& Krenczyk, D. (2017). Risk Assessment in a Parallel Production System with the Use of FMEA Method and Linguistic Variables. Computer Information Systems and Industrial Management Lecture Notes in Computer Science, 379-390, https://doi.org/10.1007/978-3-319-59105-6_32

Burduk, A. (2010). An attempt to adapt serial reliability structures for the needs of analyses and assessments of the risk in production systems. Eksploatacja i Niezawodność-Maintenance and Reliability, (3), 85-96.

Burduk, A., \& Chlebus, E. (2009). Evaluation of the risk in production systems with a parallel reliability structure. Eksploatacja i Niezawodnosc-Maintenance and Reliability, (2), 84-95.

Campbell, J. D., Jardine, A. K., \& McGlynn, J. (Eds.). (2016). Asset management excellence: optimizing equipment life-cycle decisions. CRC Press.

Chlebus, E., Helman, J., Olejarczyk, M., \& Rosienkiewicz, M. (2015). A new approach on implementing TPM in a mine - A case study. Archives of Civil and Mechanical Engineering, 15(4), 873-884, https://doi.org/10.1016/j.acme.2015.07.002

Czaplicki, J. M. (2008). Shovel-Truck Systems: Modelling, Analysis and Calculations. CRC Press.

Czaplicki, J. M. (2009). Mining equipment and systems: theory and practice of exploitation and reliability. CRC Press.

Czaplicki, J. M. (2014). Statistics for mining engineering. CRC Press.

Dhillon, B.S. (2008). Mining Equipment Reliability, Maintainability, and Safety. Springer Science \& Business Media. 
Dhillon, B.S. (2017). Engineering systems reliability, safety, and maintenance: an integrated approach. CRC Press.

Ferencz, V., Dugas, J., Prividi, D., Andrejkovič, M., Cehlár, \& M., Jurkasova Z. (2015). The implementation of knowledge-intensive services in drawing out and bottling of natural mineral water. Acta Montanistica Slovaca, 20(2), 125-140.

Hall, R. A., Daneshmend, L. K., Lipsett, M. G., \& Wong, J. (2000). Reliability analysis as a tool for surface mining equipment evaluation and selection. CIM bulletin, 78-82.

Kirjanów-Błażej, A., Jurdziak, L., Burduk, R., \& Błażej, R. (2019). Forecast of the remaining lifetime of steel cord conveyor belts based on regression methods in damage analysis identified by subsequent DiagBelt scans. Engineering Failure Analysis, 100, 119-126, https://doi.org/10.1016/j.engfailanal.2019.02.039

Kolowrocki, K. (2004). Reliability of large systems. Amsterdam: Elsevier.

Koman, M., \& Laska, Z. (2014). Rozwiązania konstrukcyjne elementów systemu transportu taśmowego O/ZG Rudna, pozwalające na zmianę kierunku przesyłu urobku. Cuprum: czasopismo naukowo-techniczne górnictwa rud, 3(72), 69-82.

Kržanović, D., Kolonja, B., \& Stevanović, D. (2015). Maximizing the net present value by applying an optimal cut-off grade for long-term planning of the copper open pits. Acta Montanistica Slovaca, 20(1), 49-61.

Kuzin, E., Gerike, B., Mamaeva, M., \& Singh, K. (2019). Diagnostics of Gearboxes of Mining Belt Conveyors Using Floating Spectral Masks. In E3S Web of Conferences (Vol. 105, p. 03011). EDP Sciences, https://doi.org/10.1051/e3sconf/201910503011

Kuric, I. (2011). New methods and trends in product development and planning. Academic Journal of Manufacturing Engineering, 9(1), 453-456.

Kuric, I., Císar, M., Tlach, V., Zajačko, I., Gál, T., \& Więcek, D. (2018). Technical diagnostics at the department of automation and production systems. In International Conference on Intelligent Systems in Production Engineering and Maintenance (474-484). Springer, Cham, https://doi.org/10.1007/978-3-319-97490346

Lazarević, Ž., Aranđelović, I., \& Kirin, S. (2018). The reliability of bucket wheel excavator-review of random mechanical failures. Tehnički vjesnik, 25(4), 1259-1264, https://doi.org/10.17559/TV-20160727170019

Leugner, T. (1996). Developing a total productive maintenance(TPM) programme. Quarry Management, 23(8), 21-25.

Ratnayake, R. C., \& Antosz, K. (2017). Risk-Based Maintenance Assessment in the Manufacturing Industry: Minimisation of Suboptimal Prioritisation. Management and Production Engineering Review, 8(1), 3845, DOI: 10.1515/mper-2017-0005

Simon, P., Zeiträg, Y., Glasschroeder, J., Gutowski, T., \& Reinhart, G. (2018). Approach for a Risk Analysis of Energy Flexible Production Systems. Procedia CIRP, 72, 677-682, http://dx.doi.org/10.1016/j.procir.2018.03.073

Szymański, Z. (2007). Badania niezawodnościowe silników napędowych maszyn górniczych. Maszyny Elektryczne: zeszyty problemowe, (78), 115-120.

Tlach, V., Císar, M., Kuric, I., \& Zajačko, I. (2017). Determination of the industrial robot positioning performance. In MATEC Web of Conferences (Vol.137, p.01004). EDP Sciences, https://doi.org/10.1051/matecconf/201713701004

Tworek, P., Tchórzewski, S., \& Valouch, P. (2018). Risk Management in Coal-Mines-Methodical Proposal for Polish and Czech Hard Coal Mining Industry. Acta Montanistica Slovaca, 23(1), 72-80.

Waters, D. (2002). Operations management producing goods and services. Harlow: Prentice Hall.

Więcek, D., Burduk, A., \& Kuric I. (2019). The use of ANN in improving efficiency and ensuring the stability of the copper ore mining process. Acta Montanistica Slovaca, 24(1), 1-14.

Więcek, D., \& Więcek, D. (2017). The influence of the methods of determining cost drivers values on the accuracy of costs estimation of the designed machine elements. In International Conference on Information Systems Architecture and Technology (pp. 78-88). Springer, Cham, https://doi.org/10.1007/978-3-319-67223-6_8

Więcek, D., Więcek, D., \& Dulina, L. (2020). Materials requirement planning with the use of activity based costing. Management Systems in Production Engineering, 28(1), 3-8, https://doi.org/10.2478/mspe-20200001

Wodecki, J., Stefaniak, P., Polak, M., \& Zimroz, R. (2017). Unsupervised Anomaly Detection for Conveyor Temperature SCADA Data. Applied Condition Monitoring Advances in Condition Monitoring of Machinery in Non-Stationary Operations, 361-369, https://doi.org/10.1007/978-3-319-61927-9_34

Wolfgang, B., \& Klaus, M. (2007). Remarks to the risk assessment for abandoned mine sites.Acta Montanistica Slovaca, Ročník 12(3), 340-348.

Zajačko, I., Gál, T., Ságová, Z., Mateichyk, V., \& Wiecek, D. (2018). Application of artificial intelligence principles in mechanical engineering. In MATEC Web of Conferences (Vol. 244, p. 01027). EDP Sciences, https://doi.org/10.1051/matecconf/201824401027 